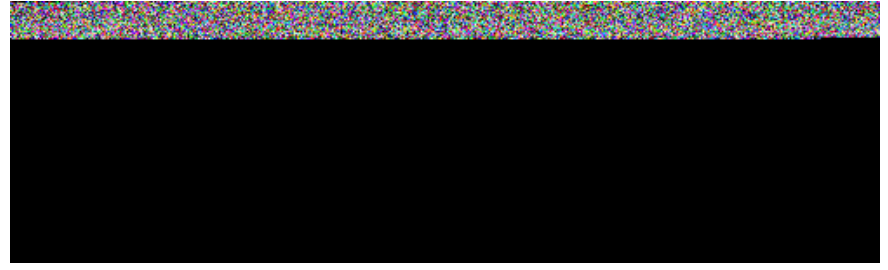

This information is current as of April 26, 2023.

\title{
Virtual Biopsy: A Reality Thanks to Advances in Radiology
}

M.F.V.V. Aragao, A.D.P. Oliveira, A.R.M.C. Lima, M.C Leal and M.M. Valenca

AJNR Am J Neuroradiol 2021, 42 (7) E37-E38

doi: https://doi.org/10.3174/ajnr.A7092

http://www.ajnr.org/content/42/7/E37 


\section{Virtual Biopsy: A Reality Thanks to Advances in Radiology}

$I_{\text {toto }}^{\text {then }}$ is fascinating when we can determine cause and effect in the topographic identification of intracranial lesions. Neurologic semiology was developed before neuroimaging existed to determine the exact location of the brain injury and its representation as a neurologic deficit or dysfunction observed during a physical examination of the patient.

A very curious symptom during the coronavirus disease 2019 (COVID-19) pandemic is a change in the sense of smell. We could consider this symptom as pathognomonic in the current context of the pandemic.

The explanation of the anosmia reported by patients with COVID-19 was controversial for some time, not always considering injury to the olfactory bulb as a probable cause. Nevertheless, with the help of neuroradiology, it is now possible to show that some patients with COVID-19 have lesions in the olfactory bulbs.

On June 1, 2020, our study was accepted, and we published 5 cases of patients with COVID-19 and injury to olfactory bulbs detected on MR imaging, which could represent microvascular injury with enhancement (breakdown of the blood-brain barrier) and/or probable hemorrhagic lesions (methemoglobin). ${ }^{1} \mathrm{We}$ were probably the first to show a microvascular phenomenon in the olfactory bulbs of patients with COVID-19. ${ }^{1}$ However, there was an interpretation that considered these changes on MR imaging as artifacts, ${ }^{2}$ and we had to explain why the findings in our study of the olfactory bulbs could not be artifacts. We showed another case with a lesion in the olfactory bulb on FLAIR and echo-spoiled gradient-echo T1WI, which could represent methemoglobin. ${ }^{3}$ We finished our Reply saying, "We think all would agree that anatomopathologic studies are necessary to better define neuroradiologic interpretation." ${ }^{3}$ Finally, Lee et $\mathrm{al}^{4}$ demonstrated, in an extremely elegant postmortem histopathology study using much more sophisticated tools (eg, an 11.7T scanner), what we had suggested in vivo previously on the $1.5 \mathrm{~T} \mathrm{MR}$ imaging: ${ }^{1}$ The change of the sense of smell represents microvascular injury $^{1,3}$ (areas of fibrinogen leakage, thinned basal lamina, and hemorrhagic lesions in the brain and olfactory bulbs) ${ }^{4}$ and not artifacts as is also shown in Figure.

- Indicates open access to non-subscribers at www.ajnr.org http://dx.doi.org/10.3174/ajnr.A7092
In conclusion, once again, there is evidence that our neuroradiology tools can function as a virtual biopsy to correctly diagnose the topography of the lesion and discover the etiology, especially when it is not possible to obtain histopathological evidence.

\section{REFERENCES}

1. Aragao MFVV Leal MC, Cartaxo FO, et al. Anosmia in COVID-19 associated with injury to the olfactory bulbs evident on MRI. AJNR Am J Neuroradiol 2020;41:1703-06 CrossRef Medline

2. Mamourian A. Seeing what we expect to see in COVID-19. AJNR Am J Neuroradiol 2021;42:E1 CrossRef Medline

3. Aragao MFVV, Leal MC, Fonseca TM, et al. Reply. AJNR Am J Neuroradiol 2021;42:E2-E3 CrossRef Medline

4. Lee MH, Perl DP, Nair G, et al. Microvascular injury in the brains of patients with Covid-19. N Engl J Med 2021;384:481-83 CrossRef Medline 


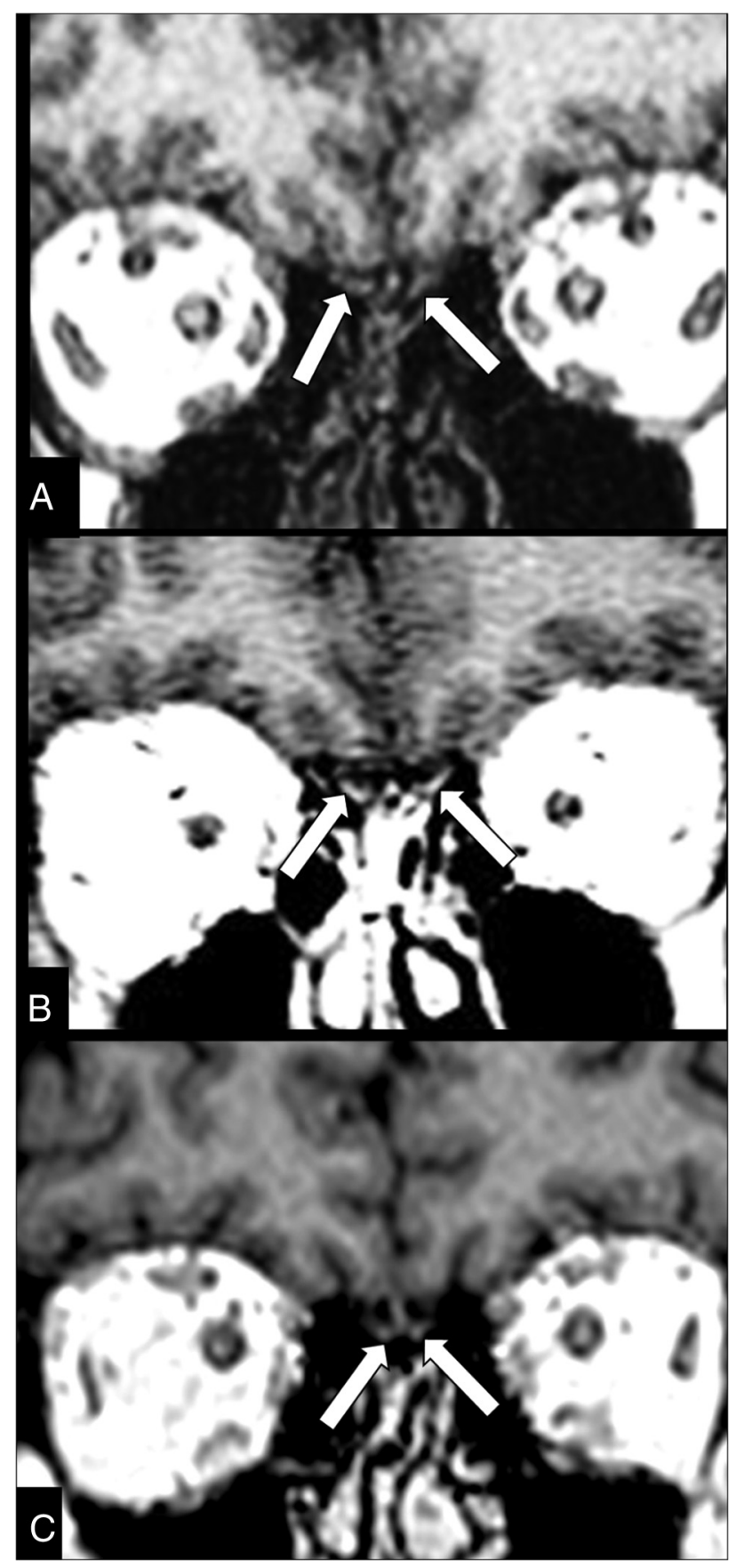

FIGURE. Brain MR imaging of a woman in her 40's with confirmed COVID-19 shows injury of the olfactory bulbs, within 7 days of onset of the disease. A real-time polymerase chain reaction of a nasopharyngeal swab detected Severe Acute Respiratory Syndrome coronavirus 2, which was negative on her CSF. The MR imaging shows that the olfactory bulbs are oval images with signal intensity similar to that of gray matter on precontrast TIWI (A, arrows), being hypointense. On postcontrast TIWI ( $B$, arrows), the olfactory bulbs show abnormal enhancement and become hyperintense, suggesting injury with breakdown of the brain-blood barrier. Two months later, the followup MR imaging shows that the contrast enhancement of the olfactory bulbs has completely disappeared and they have a normal appearance, being hypointense and similar to the gray matter on coronal postcontrast TIWI (C, arrows). 